\title{
IV. Responsibility Sharing
}

\author{
Astri Suhrke and Asha Hans
}

The authors propose a bifurcated responsibility sharing system, in which protection would normally be provided within the refugee's region of origin, with selective extra-regional protection to meet special needs cases. The major contribution of states outside the region would be a commitment to fiscal burden sharing. This system is argued to reflect a situation-specific morality, taking into account the realpolitik concerns that make a more elaborate and universalized system of humane responsibility sharing unworkable. This is a substantially abbreviated version of the authors' original work. Please refer to the notice at the end of this section if you are interested in obtaining a full copy of the paper, which is expected to be published in mid-1996.

Most of the world's refugee movements are not subject to arranged distribution among receiving states. Spontaneity and anarchy, rather than organized distribution of asylum seekers and refugees, constitute the norm. Yet, the present system has severe shortcomings that are well known: it entails systematic biases in cost distribution among receiving states (most refugees originate in, and are accommodated, in the world's poorer countries); it encourages destructive beggar-thy-neighbour policies (as states try unilaterally to shift refugees onto the "next state" in the manner of protectionist states in a trading system); and the random characteristics of the system accentuate the hardship inflicted on refugees (who may/may not happen to arrive in an area that provides protection).

Professor Astri Suhrke, Director of Research, Department of Social Sciences and Development, Chr. Michelsen Institute, Norway.

Professor Asha Hans, Department of Political Science, University of Bhubaneswar, Orissa, India.
In both the UN and regional interstate fora, the discussion of principled burden sharing with respect to refugees has focused on financial aid rather than redistribution of refugees. Developing countries, while hosting most refugees, have not demanded generalized sharing schemes whereby the North would help to off-load the South. Demands for sharing have only been made in particular and exceptional cases. Apart from these, states seem to tacitly agree to accept present imbalances in the global distribution of refugees. Precisely for that reason, however, financial aid to states that host large refugee populations has long been regarded as essential and self-evidently necessary, although practice typically has lagged behind principle.

The obstacles to a generalized scheme for significant redistribution of refugees do not merely lie in the unwillingness of the North to open its doors, as many critics charge. Many refugees prefer to stay near their home in order eventually to return. Political and military reasons may have the same effect as displaced persons take up arms to regain their territory (e.g. the Palestinians) or to overthrow a regime (e.g. the Afghan mujahedeen). Some celebrated cases of transfer out of the region have had miserable results and been discontinued.

Many governments willingly host a considerable refugee burden even though their own countries suffer from poverty and instability. The reasons range from a sense of responsibility to national security concerns. If participating in a generalized scheme of sharing, on the other hand, states might have reduced autonomy in selecting both the number and nationality of refugees for admission.

Occasionally states have joined in redistributive schemes, but only as ad hoc responses to massive outflows. In these cases, states used a combination of humanitarian, immigration and political criteria for admission, and set their own quotas for intake. Taken as a whole these criteria constitute implicit rules for sharing and suggest what the present state system can accommodate. Similar schemes may well be established in response to particular future emergencies (as some European states tried but failed to do for refugees from former Yugoslavia). If so, the criteria for sharing in past emergencies may well be applied. Since previous schemes contained many elements of durable solutions, this seems reasonable.

Proposals for improved responsibility schemes which are anchored in the past and the present-rather than an idealized future-could reasonably start by focusing on means to provide improved protection within the area of first asylum. Financial transfers to compensate for costs incurred by first asylum states would be essential. If asylum is likely to be long-term or return impossible, settlement and redistribution within the region would seem the least problematic option, as the case studies suggest. A strong case can be made for resettling special individual cases wherever their needs would be best met. To proceed further towards formalized and enduring schemes for redistribution would require changes in the underlying conditions which affect states' attitudes towards sharing.

\section{Burden Sharing Versus Burden Shifting}

States tend to accept refugees on the basis of three kinds of considerations: (i) legal and humanitarian concerns, (ii) fear of greater international disorder which may occur if refugees are not helped, and (iii) national interests arising from whatever specific economic or political considerations are relevant 
in the particular case (e.g. ethnic kin, demand for labour, foreign policy).

Any burden sharing scheme must be based on the realpolitik assumption that legal obligations and humanitarian considerations alone rarely suffice to persuade states to admit refugees (unless the numbers are quite small). Accepting this premise, we can ask under what conditions states would be willing to accept a principled commitment to participate in a burden sharing scheme.

A global sharing scheme is morally attractive. A regionalized reformulation of refugee law, on the other hand, presents certain advantages:

a) refugees are likely to come anyway.

Hence, the notion of avoiding greater disorder carries more weight than in a global context, assuming that regional states have at least a second-priority interest in regional order;

b) most states are likely to be more concerned with (or involved in) conflicts within their region than outside. Hence, there is likely to be a greater sense of responsibility or political involvement with the refugees;

c) existing patterns of regional cooperation may facilitate extension to refugee matters; and

d) the sense of commonality which prevails within a region will incline states to view incorporation more easily than if the refugees came from outside the regions.

Yet, two important questions remain. How is a region defined and, what form will regional cooperation on refugee matters take? A minimalist scheme for responsibility sharing might amount to exclusion and tokenism (as is the current West European tendency), or a sharing which amounts to shifting (which the ASEAN countries did with respect to the Vietnamese refugees).

States participating in a systematized and long-term burden sharing scheme for refugees will probably insist on greater control over both membership and likely caseload. The latter would involve some control over the causes of outflows as well as initial status determination. At present these critical conditions are lacking, as the "spot contract" nature of the international refugee regime indicates. More importantly, states can unilaterally and with some ease insulate themselves from distant refugee flows; even refugees within the region can be kept out-if not entirely - by means of interdiction, restrictions and border controls of various kinds. If this leads to lack of protection, or concentrated impact in one area, both local and international disorder may follow. Yet, these are "ifs", as is the impact of eventual disorders on other states; recent conflicts-from the war in former Yugoslavia to the genocide in Rwanda-demonstrate how readily most states can in fact insulate themselves from the consequences of violence elsewhere. Under these circumstances, states will be tempted to shift rather than share refugees.

It should be made clear that a regionally-oriented regime does not mean exclusive regional responsibility for "people-sharing". Under this system, a proportion of the world's total refugee population would be transferred out of the region when this is warranted for reasons of protection, special vulnerability, or family reunification. Other refugees can be expected to move out of the region on their own (spontaneous asylum seekers). Hence, there is no absolute separation.

Yet, it is clear that the overwhelming number of refugees would remain within their region of origin. Whether or not this is morally repugnant is less clear. Redistribution can have an adverse impact on the refugees, may create a backlash in the receiving societies, and, on the level of morality of states, may affect the security and power of sending as well as receiving nations. From this perspective, situation-specific morality rather than general principles seems to prevail.

\section{Ricint Riports}

\section{- Somall Refugees in Toronto: A Profile}

By Edward Opoku-Dapaah

ISBN 1-55014-278-x, 130 pp, $\$ 12.95$.

This is the first comprehensive study of Somali refugees in Toronto. It examines the social, residential, and linguistic characteristic of Somalis, their participation in the local economy, and the activity of Somali community organizations. The report also contains valuable suggestions and recommendations concerning suitable and more efficient service delivery to this com. munity.

\section{- Cambodian Refugees in Ontario:} An Evaluation of Resettlement and Adaptation

By Janet McLellan,

ISBN 1-55014-267-4, 142 pp,, 72.95.

This major study of Cambodian refugees in Ontario examines the effects of various forms of sponsorship on Cambodian resettement. It also focuses and the linguistic, economic, educational, training and social dimensions of the whole process of adaptation. The delivery of services by govern. mental and NGO agencies as well as the effects of the past traumatic experiences of genocide and mass starvation on Cambodian refugees are fully discussed.

\section{- Refugee Families and Children:} A Directory for Service Providers in Metro Toronto Compiled by

Dr. John Morris and Lydia Sawicki. ISBN 1-55014-285-2,39 pp. . 86.95 . This directory is designed for service providers who work with refugee families and children in Metro Toronto. Its aim is to improve service provision through networking and the sharing of training opportunities.

Available from

York Lanes Press 